\title{
THE EFFECT OF HIGH-PRESSURE PROCESSING ON ENTERAL FOOD MADE FROM FRESH OR SEMI-FINISHED INGREDIENTS
}

\author{
Liene Ozola*, Solvita Kampuse, Ruta Galoburda \\ Department of Food Technology, Faculty of Food Technology, Latvia University of Agriculture, Rigas iela 22, Jelgava, Latvia, \\ *e-mail: lieneozola8@inbox.lv
}

\begin{abstract}
The enteral feeding can be defined as a delivery of nutrients directly into the stomach, called also enteral nutrition. Dietetic products for enteral nutrition are a specific group of products designed to provide nutrients to the human body in case of various diseases and after surgery, when the daily intake of the product is affected. Today market offers special dietetic products, which are supplemented with synthetic vitamins and minerals, which bioavailability in the body is lower than that of natural organic complexes. Therefore it is important to develop special dietetic products from natural raw materials. The aim of this study was to analyse the effect of high-pressure processing on bioactive compounds in the enteral products. For this research enteral food was made using fresh or semi-finished fruit and vegetable juices. Products were processed applying high pressure, namely $400 \mathrm{MPa}, 500 \mathrm{MPa}$ and $600 \mathrm{MPa}$ for 5 minutes at room temperature. All samples were tested for their content of vitamin C, total carotenes, anthocyanins, total phenols and antioxidant activity, as the control untreated enteral food samples were used. The obtained data showed that samples made from semifinished juices have higher contents of vitamin $\mathrm{C}$ and total anthocyanins than samples prepared from fresh juices. Similarly this was observed with total phenol content where after high-pressure treatment in samples made from heated juices it was more stable and had in higher amounts than in samples from fresh ingredients. There were no significant differences in the content of bioactive compounds between products treated at different pressures.
\end{abstract}

Keywords: vitamin C, total carotene, total phenols, antioxidant activity.

\section{Introduction}

Enteral nutrition (EN) by means of oral nutrition supplements (ONS) and if necessary tube feeding (TF) offers the possibility of increasing or ensuring nutrient intake in cases where food intake is inadequate (Weimann et al., 2006). EN is only used for patients with a sufficient digestion where the food can be digested and nutrients assimilated in the body of a specially prepared diet (Rozenbergs, 2011). Enteral feeding is a method of supplying nutrients (oral food and fluids) using nasogastric, gastrostomy or jejunostomy feeding, which are sometimes referred to as enteral tube feeding (Jones et al., 2011).

There can be several types of EN, depending on the intended use and the specific needs of the patient, so creating foodstuff from natural ingredients can be challenging when it comes to producing microbially safe and stable products with necessary health attributes. Taking all of this into consideration high pressure processing (HPP) has emerged as a novel, additive-free food preservation technology that has been scientifically and commercially proven to be very useful (Barba et al., 2015).

High-pressure processing (HPP) is a method where very high pressure from 100 to $1000 \mathrm{MPa}$ is used to process packaged food using liquids a medium to transmit pressure. Using HPP it is possible to process food in a wide range of temperaturesfrom $-20^{\circ} \mathrm{C}$ to $100{ }^{\circ} \mathrm{C}$ for a certain time (typically from few seconds to 30 minutes). This allows eliminating harmful pathogens and microorganisms that are responsible for vegetative spoilage and to inactivate enzymes with minimal modifications in nutritional and sensory quality (Andrés et al., 2016, 2016b; CarbonellCapella et al., 2013).

Aroma compounds, vitamins and minerals are rarely affected by HPP, because of their low molecular weight and low compressibility of covalent bonds, however this doesn't apply to macromolecules such as proteins and starch which can change their native structure during HPP similarly to thermal treatments (Barba et al., 2015). The aim of this study was to analyse the effect of high pressure processing on the shelf life of enteral products made from fresh and heated (semi-finished) fruit and vegetable juices.

\section{Materials and Methods \\ Sample preparation}

For the purpose of this research samples of the same recipe enteral food was prepared ensuring $100 \mathrm{kcal}$ intake per $161.25 \mathrm{~g}$ of product by using juices from blackcurrant, beet, pumpkin, cabbage, Jerusalem artichoke and whey protein, canola oil, cod liver oil, iodized salt. For one part of the experiment fresh juices (obtained from raw fruits and vegetables grown in organic management system), for the other part juices previously vacuum cooked (prepared by Ltd 'KEEFA' 'Natural Food manufacturer' from the same raw material) were used. One average sample of each set of ingredients was made to be divided between 18 individually packaged $100 \mathrm{ml}$ PP bottles (Kartell, Italy) for the HPP. Before applying the HPP each bottle was vacuum packaged in a polymer film (PA/PE) to prevent any product leakage during processing as a result of applied pressure.

\section{High-pressure processing}

The HPP was carried out using ISO-Lab High Pressure Pilot Food Processor (S-FL-100-250-09-W, Stansted Fluid Power Ltd., Essex, UK) in a 2.0 L pressure vessel. A propylene glycol, water mix $(1: 2 \mathrm{v} / \mathrm{v})$ was used as the pressure transmitting liquid (Kirse et al., 2015).

Both of the experimental groups were subjected to high pressure processing under $400 \mathrm{MPa}, 500 \mathrm{MPa}$ and $600 \mathrm{MPa}$ for 5 minutes at room temperature. Due to pressure increase the product temperature increased by 
$15^{\circ} \mathrm{C}$ during pressurization at $400 \mathrm{MPa}$, by $17^{\circ} \mathrm{C}$ at $500 \mathrm{MPa}$ and by $20^{\circ} \mathrm{C}$ at $600 \mathrm{MPa}$.

After product processing, samples (Table 1) were stored at room temperature in direct light to observe the changes of bioactive compound content during storage. Obtained results were compared depending on the type of used ingredients for the preparation of products and the selected HPP modes. For initial comparison of the HPP impact on both group samples control tests were done with samples without the use of the HPP.

Table 1

Abbreviations used in sample identification

\begin{tabular}{lcc}
\hline $\begin{array}{l}\text { Sample } \\
\text { abbreviation }\end{array}$ & Type of juices & Applied HPP \\
\hline Fresh & Fresh & not applied \\
Heated & Heated & not applied \\
I AS & Fresh & 400 \\
II AS & Fresh & 500 \\
III AS & Fresh & 600 \\
I AP & Heated & 400 \\
II AP & Heated & 500 \\
III AP & Heated & 600 \\
\hline
\end{tabular}

The quality changes of the samples during the storage were evaluated by detection of vitamin $\mathrm{C}$, soluble solids content, $\mathrm{pH}$ value, total carotenes, total anthocyanins, total phenols, and antiradical activity. The microbial safety was tested with the detection of total plate count, coliforms, molds, and yeasts.

\section{Microbiological analyses}

Microbiological testing of enteral food was completed using $90 \mathrm{ml}$ of $0.5 \%$ sterile peptone water solution to which $10 \mathrm{ml}$ of enteral food was added and mixed. The mixture was pour-plated in duplicate for determination of total plate count (TPC) according to standard LVS EN ISO 4833:2003 (Ref. No. 01-14, Sharlau, nutrient agar, incubation at $30^{\circ} \mathrm{C}$ for $72 \mathrm{~h}$ ); Coliforms according to standard LVS ISO 7251:2005 (Ref. No. 401460, Sharlau ENDO agar, incubation at $37^{\circ} \mathrm{C}$ for $24 \mathrm{~h}$ ); mold fungi and yeast cells according to standard ISO 21257-2:2008 (Ref.No.01-111, MRS agar, incubation at $27^{\circ} \mathrm{C}$ for $48 \mathrm{~h}$ (yeast cells) and 5 to 7 days (mold fungi).

Microbiological safety of enteral food was evaluated according to the guidelines by Cabinet of Ministers, Latvia regulation No 441/2016 for Vegetable jams, purees and similar products which sets allowed limits for TPC at $5 \cdot 10^{3} \mathrm{CFU} \mathrm{g}^{-1}$; presence of Coliforms per $1 \mathrm{~g}$ of product is not allowed; Mold fungi and yeast cells no more than $50 \mathrm{CFU} \mathrm{g}{ }^{-1}$.

Soluble solids content

The soluble solids content (Brix\%) was measured with digital refractometer Refracto 30GS (Mettler Toledo, Japan) using standard method ISO 2173:2003 Fruit and vegetable products - Determination of soluble solids - Refractometric method. Measurements were carried out in five replications.

$p H$

$\mathrm{pH}$ was measured by $\mathrm{pH}-$ meter (Lutron electronic enterprise CO., Ltd., UK) using standard method LVS
ISO 5542:2010. Measurements were carried out in two replications.

Vitamin C

Content of vitamin $\mathrm{C}$ was determined according to iodine method as described by (Kerch et al., 2011). This method determines L-ascorbic acid, which is the reduced form of ascorbic acid. Measurements were carried out in four replications.

\section{Total carotenes}

Total carotenes were analysed by spectrophotometric method using UV/VIS spectrophotometer Jenway 6705 (Bibby Scientific Ltd., UK), at $440 \mathrm{~nm}$ described by Kampuse et al. (2015). The content of carotenes $\left(\mathrm{mg} 100 \mathrm{~g}^{-1}\right.$ ) was calculated in four replications.

\section{Total anthocyanins}

Total anthocyanin content was determined by spectrophotometric method according to (Moor et al, 2005), detected on spectrophotometer Jenway 6705 at wavelength of $540 \mathrm{~nm}$. Measurements were carried out in two replications.

\section{Total phenol content}

Total Phenol content was determined according to the Folin-Ciocalteu method (Yu et al., 2003) with modifications: to $0.5 \mathrm{~mL}$ of extracted sample add $2.5 \mathrm{~mL}$ of $0.2 \mathrm{~N}$ Folin-Ciocalteu reagent, that has been diluted ten times with distilled water; after 5 minutes $2.0 \mathrm{~mL}$ of $7.5 \% \mathrm{NaCO}_{3}$ was added; the resulting solution was mixed and allowed to stand for 30 minutes at $18 \pm 1^{\circ} \mathrm{C}$ in a dark place; absorption was read at $760 \mathrm{~nm}$ using JENWAY 6300 (Banoworld Scientific Ltf., UK) spectrophotometer (Priecina et al., 2014).

Measurements were carried out in six replications from two separately weighed samples.

Antiradical scavenging activity (DPPH)

The antiradical scavenging activity of extracts was determined on the radical scavenging ability in reacting with stable 2,2-diphenil-1-picrylhydrazyl (DPPH) free radical according to researchers group (Yu et al., 2003) with modifications: to $0.5 \mathrm{~mL}$ of extracted sample $3.5 \mathrm{~mL}$ freshly made DPPH solution was added $(4 \mathrm{mg}$ of DPPH reagent was dissolved in $100 \mathrm{ml}$ pure ethanol); the mixture was shaken and kept in the dark place at $18 \pm 1{ }^{\circ} \mathrm{C}$ for $30 \mathrm{~min}$; absorbance was measured at $517 \mathrm{~nm}$ using JENWAY 6300 Spectrophotometer (Priecina et al., 2014).

Measurements were carried out in six replications from two separately weighed samples.

\section{Statistical analysis}

The obtained data was processed using 'Microsoft Office Excel' 2007 version, differences between the results were analysed using ANOVA: Two-factor with replication. The obtained results are presented as their mean with standard deviations. Differences among results were considered to be significant if $\mathrm{p}$-value $<\alpha_{0.05}$. 


\section{Results and Discussion}

Effect of the HPP and storage on microbial safety

Microbial counts were evaluated for both types of ingredients high pressure processed samples and also to control samples without HPP.

No coliforms were found in the evaluated samples, also mold fungi where only detected in control samples made from fresh juices ( $\left.2 \mathrm{CUF} \mathrm{g}^{-1}\right)$ before storage.

Control samples weren't tested during storage, only their initial results were used for evaluation of the efficiency of the HPP. The total plate count is shown in Table 2 where the mean value of untreated fresh juice samples was $3.3 \cdot 10^{2} \mathrm{CUF} \mathrm{g}^{-1}$ and for semi-finished juices $5 \mathrm{CUF}^{-1}$. The testing showed that after the HPP all samples were microbiologically safe and with both types of used ingredients (fresh and semi-finished) the applied pressures (400 MPa, $500 \mathrm{MPa}, 600 \mathrm{MPa}$ ) were sufficient for reduction of microbial activity. This coincides with findings of Andrés et al. (2016) on microbial shelf life on refrigerated milk- and soysmoothies. However during the four weeks of storage only samples made from semi-finishedingredients stayed microbiologically safe, but sampeles from fresh juices after the week 1 started to show contamination, which gradually grew and at the week 2 exceeded the allowed yeast cell count $50 \mathrm{CUF} \mathrm{g}^{-1}$ and became unsuitable for further testing Table 2.

The highest TPC after the week 1 was in the sample I AS treated at $400 \mathrm{MPa}-62 \mathrm{CUF} \mathrm{g}^{-1}$ and the lowest in sample III AS (500 MPa pressure) $36 \mathrm{CUF} \mathrm{g}^{-1}$ but no significant difference was found between the applied pressure effect on TPC.

Table 2

Total plate count, CUF $\mathrm{g}^{-1}$

\begin{tabular}{lccccc}
\hline Sample & \multicolumn{5}{c}{ Storage time } \\
\cline { 2 - 6 } & $\begin{array}{c}\text { Before } \\
\text { storage }\end{array}$ & week 1 & week 2 & week 3 & week 4 \\
\hline Fresh & $3.3 \cdot 10^{2}$ & NA & NA & NA & NA \\
Heated & 5 & NA & NA & NA & NA \\
I AS & ND & 62 & $1.1 \cdot 10^{2}$ & NA & NA \\
II AS & ND & 59 & 95 & NA & NA \\
III AS & ND & 36 & $1.02 \cdot 10^{2}$ & NA & NA \\
I AP & ND & ND & ND & ND & ND \\
II AP & ND & ND & ND & ND & ND \\
IIIAP & ND & ND & ND & ND & ND \\
\hline ND - not detected, NA - not analysed &
\end{tabular}

As mentioned before only the growth of yeast cells (Table 3) was observed in enteral food samples during storage where the mean value of untreated fresh ingredient EN food was 8.4.10 $0^{2} \mathrm{CUF} \mathrm{g}^{-1}$ and for heated ingredient $\mathrm{EN}$ food $8 \mathrm{CUF}^{-1}$. The highest yeast cell count was in the sample I AS (HPP at $400 \mathrm{MPa}$ ) after week 1 it was $39 \mathrm{CUF} \mathrm{g}^{-1}$, after the week 2 cell count grew up to $1.09 \cdot 10^{2} \mathrm{CUF} \mathrm{g}^{-1}$. A similar change was detected with the rest of the samples.

Table 3

Yeast cell count, $\mathrm{CUF} \mathrm{g}^{-1}$

\begin{tabular}{lccccc}
\hline Sample & \multicolumn{5}{c}{ Storage time } \\
\cline { 2 - 6 } & $\begin{array}{c}\text { Before } \\
\text { storage }\end{array}$ & week 1 & week 2 & week 3 & week 4 \\
\hline Fresh & $8.4 \cdot 10^{2}$ & NA & NA & NA & NA \\
Heated & 8 & NA & NA & NA & NA \\
I AS & ND & 39 & $1.09 \cdot 10^{2}$ & NA & NA \\
II AS & ND & 37.5 & 95 & NA & NA \\
III AS & ND & 36 & 98.5 & NA & NA \\
I AP & ND & ND & ND & ND & ND \\
II AP & ND & ND & ND & ND & ND \\
IIIAP & ND & ND & ND & ND & ND \\
ND - not detected, NA - not analysed
\end{tabular}

The effect of the HPP and storage on soluble solids and $\mathrm{pH}$

Both soluble solids and $\mathrm{pH}$ showed no significant change after the HPP or storage, however enteral food made from fresh juices had higher content of soluble solids 12 Brix \% on average than those made from semifinished juices, which on average was 11 Brix $\%$. Similarly, enteral food from fresh juices had $\mathrm{pH} 5$, but from semi-finished juices $\mathrm{pH} 4.5$. These findings coincide with other researcher findings (Andrés et al., 2016; Landl et al., 2010) of no significant change in $\mathrm{pH}$ and soluble solids during refrigerated storage of the HPP treated samples.

Effect of the HPP and storage on vitamin C content The content of vitamin C (Table 4) in the sample without high pressure processing made from fresh ingredients was $25 \pm 3.46 \mathrm{mg} 100 \mathrm{~g} \mathrm{~g}^{-1}$, but in sample made

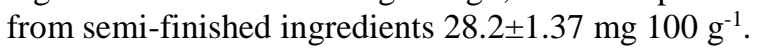

The high pressure processing initially shows better vitamin $C$ retention in the samples made from semifinished ingredients but after 2 weeks of storage the loss of vitamin $\mathrm{C}$ on average was $50 \%$. However samples made from fresh ingredients showed a 33 to $65 \%$ decrease right after applying HPP. This could be explained with the enzymatic activity in fresh juices where enzymes keep deteriorate ascorbic acid contrary to semi-finished ingredients where enzymatic inactivation was achieved by heat treatment. The statistical analysis showed a significant difference in content of vitamin $\mathrm{C}$ between samples made from different groups of ingredients $(p<0.05)$ and a slight difference between the applied pressure $(\mathrm{p}=0.003)$ for samples before storage.

Table 4

Content of vitamin $\mathrm{C}, \mathrm{mg} 100 \mathrm{~g}^{-1}$

\begin{tabular}{|c|c|c|c|c|c|}
\hline \multirow[t]{2}{*}{ Sample } & \multicolumn{5}{|c|}{ Storage time } \\
\hline & Before storage & week 1 & week 2 & week 3 & week 4 \\
\hline Fresh & $25.0 \pm 3.5$ & NA & NA & NA & NA \\
\hline Heated & $28.2 \pm 1.4$ & NA & NA & NA & NA \\
\hline I AS & $17.4 \pm 1.3$ & $20.5 \pm 2.9$ & $11.4 \pm 1.5$ & NA & NA \\
\hline II AS & $15.9 \pm 2.8$ & $19.2 \pm 1.1$ & $13.7 \pm 1.4$ & NA & NA \\
\hline III AS & $11.1 \pm 1.8$ & $16.2 \pm 2.5$ & $14.5 \pm 1.4$ & NA & NA \\
\hline I AP & $29.8 \pm 1.0$ & $25.5 \pm 1.1$ & $14.6 \pm 1.4$ & $14.6 \pm 1.4$ & $13.4 \pm 1.4$ \\
\hline II AP & $33.3 \pm 2.2$ & $27.4 \pm 2.5$ & $13.3 \pm 1.4$ & $13.3 \pm 1.4$ & $12.8 \pm 2.1$ \\
\hline IIIAP & $30.8 \pm 0.1$ & $29.5 \pm 1.3$ & $13.5 \pm 1.4$ & $14.5 \pm 1.4$ & $13.3 \pm 1.2$ \\
\hline
\end{tabular}


The highest vitamin $\mathrm{C}$ content was $33.3 \pm 2.24 \mathrm{mg} 100 \mathrm{~g}^{1}$ in the sample II AP (made from semi-finished ingredients processed at $500 \mathrm{MPa}$ ) but the lowest in the sample III AS (fresh ingredients, processed at $600 \mathrm{MPa}) 11.1 \pm 1.83 \mathrm{mg} 100 \mathrm{~g}^{-1}$. It is partially possible to link the obtained data to other studies on this subject however the storage in those was mostly refrigerated. For example Andrés et al. (2016) also show a more rapid loss of vitamin $\mathrm{C}$, but on the day $30(32 \%$ for sample processed at $450 \mathrm{MPa}$ and $36 \%$ for $600 \mathrm{MPa}$ ). The statistical analysis showed a significant loss of vitamin $\mathrm{C}$ during storage for samples from both ingredient groups $(\mathrm{p}<0.05)$ and also between applied pressures for samples made from fresh ingredients (I AS, II AS, III AS) $\mathrm{p}=0.006$, these results are consistent with Andrés et al. (2016), Oey et al. (2008) who also reported the enhanced degradation rate of vitamin $\mathrm{C}$ by increased pressure.

The effect of the HPP and storage on total carotene content

Similarly to the content of vitamin C, also content of total carotenes (TC) show a significant difference between enteral food samples made from fresh juices which is lower and samples made from semi-finished juices. The lowest amount of TC (Table 5) was in I AS $\left(0.15 \pm 0.01 \mathrm{mg} 100 \mathrm{~g}^{-1}\right)$, but the highest in the sample processed at the same pressure made from semi-finished ingredients I AP $\left(0.44 \pm 0.01 \mathrm{mg} 100 \mathrm{~g}^{-1}\right)$ immediately after processing. No significant difference was found between samples of fresh juice enteral food and semi-finished ingredient EN food without the HPP treatment, but such was found in all samples after the HPP $(\mathrm{p}<0.05)$. EN food made from fresh juices showed a significant degradation of TC which isn't supported by other author findings, but the samples made from semi-finished ingredients didn't show such degradation.

Evaluating the obtained data no direct coherence of total carotenes change during storage can be lined, but it does show a tendency of degradation with every week of storage and increasing pressure for semi-finished ingredient EN food samples. The uneven data from this study could be indicative of an uneven distribution of oil and oil-soluble ingredients during filling. Barba et al. (2015) also reported that the HPP treatment can increase extractable carotenoid amount in plant-based products explaining it with the permeabilization of the plasma membrane cell and denaturation of the carotenoid-binding protein induced by the HPP (400-600 MPa/20-25 $\mathrm{C} / 2-5 \mathrm{~min}$ ).

The effect of the HPP and storage on total anthocyanin content

Evaluating total anthocyanin content a significant difference $(p<0.05)$ between fresh and semi-finished ingredient enteral food samples and a slight difference between the applied pressure $(p=0.03)$ was detected before storage and also during storage for all samples $(p<0.05)$. This however does not apply to semi-finished ingredient enteral foods that show the highest total anthocyanin content from $2.25 \pm 0.02 \mathrm{mg} 100 \mathrm{~g}^{-1}$ (II AP)

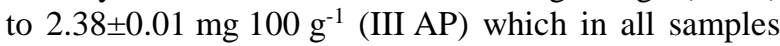
similarly decreased during storage Figure 1.

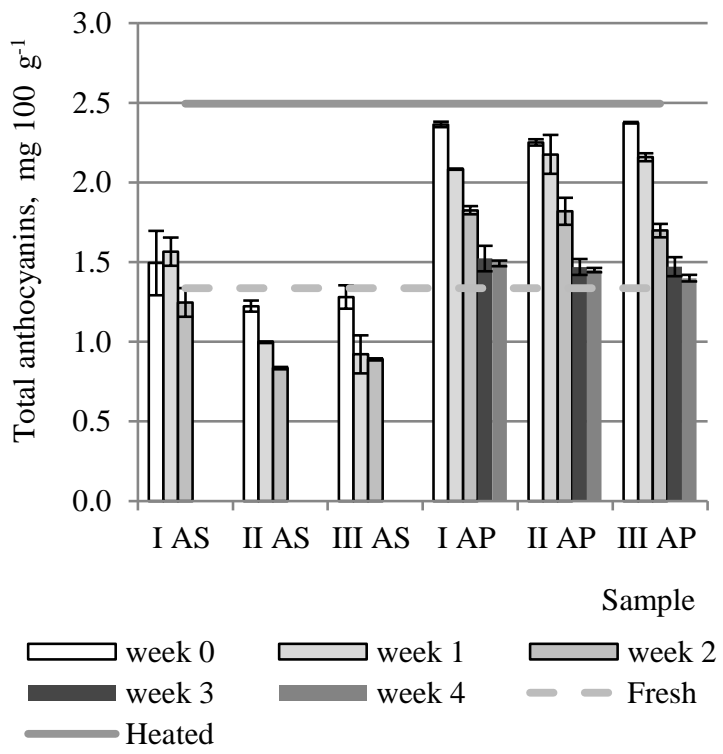

Figure 1. Content of total anthocyanins, mg $100 \mathrm{~g}^{-1}$

There was a significant difference between processing pressures on fresh juice samples. The more divers' changes with these samples could also be explained with one medium weight difference and some authors do mention that some enzymatic activity is still present in products even after the HPP treatment which makes these samples unstable during storage (Denoya et al., 2016).

Table 5

Content of total carotene, $\mathrm{mg} 100 \mathrm{~g}^{-1}$

\begin{tabular}{lccccc}
\hline \multirow{1}{*}{ Sample } & \multicolumn{3}{c}{ Storage time } \\
\cline { 2 - 6 } & Before storage & week 1 & week 2 & week 3 & week 4 \\
\hline Fresh & $0.44 \pm 0.00$ & NA & NA & NA & NA \\
Heated & $0.44 \pm 0.02$ & NA & NA & NA & NA \\
I AS & $0.15 \pm 0.01$ & $0.20 \pm 0.03$ & $0.16 \pm 0.02$ & NA & NA \\
II AS & $0.18 \pm 0.04$ & $0.16 \pm 0.01$ & $0.19 \pm 0.02$ & NA & NA \\
III AS & $0.21 \pm 0.02$ & $0.13 \pm 0.00$ & $0.16 \pm 0.02$ & NA & NA \\
I AP & $0.42 \pm 0.02$ & $0.44 \pm 0.01$ & $0.37 \pm 0.01$ & $0.37 \pm 0.02$ & $0.24 \pm 0.01$ \\
II AP & $0.25 \pm 0.01$ & $0.38 \pm 0.03$ & $0.35 \pm 0.01$ & $0.38 \pm 0.01$ & $0.32 \pm 0.04$ \\
IIIAP & $0.35 \pm 0.00$ & $0.32 \pm 0.00$ & $0.34 \pm 0.01$ & $0.37 \pm 0.00$ & $0.33 \pm 0.00$ \\
\hline
\end{tabular}

$\mathrm{NA}$ - not analysed 
Content of total phenols, mg GAE $100 \mathrm{~g}^{-1}$

\begin{tabular}{|c|c|c|c|c|c|}
\hline \multirow[t]{2}{*}{ Sample } & \multicolumn{5}{|c|}{ Storage time } \\
\hline & Before storage & week 1 & week 2 & week 3 & week 4 \\
\hline Fresh & $52.15 \pm 4.16$ & $\mathrm{NA}$ & NA & $\mathrm{NA}$ & NA \\
\hline Heated & $49.62 \pm 3.15$ & NA & NA & NA & NA \\
\hline I AS & $36.08 \pm 6.37$ & $48.57 \pm 7.45$ & $38.91 \pm 3.51$ & NA & NA \\
\hline II AS & $34.56 \pm 5.20$ & $50.82 \pm 6.98$ & $47.33 \pm 0.98$ & NA & NA \\
\hline III AS & $33.52 \pm 4.34$ & $46.76 \pm 3.13$ & $50.40 \pm 4.33$ & NA & NA \\
\hline I AP & $49.201 \pm 2.29$ & $55.95 \pm 4.47$ & $39.87 \pm 4.01$ & $36.61 \pm 2.49$ & $31.07 \pm 3.50$ \\
\hline II AP & $45.981 \pm 2.84$ & $54.06 \pm 4.13$ & $48.70 \pm 3.48$ & $33.03 \pm 3.91$ & $28.07 \pm 3.23$ \\
\hline IIIAP & $46.492 \pm 2.33$ & $51.28 \pm 4.29$ & $47.59 \pm 4.87$ & $32.78 \pm 3.92$ & $28.61 \pm 3.93$ \\
\hline
\end{tabular}

NA - not analysed

The effect of the HPP and storage on total phenol content

The total phenol content (Table 6) after HPP showed a significant difference between used ingredient groups, but an increase of total phenols content was detected during storage, which has been reported also by Andrés et al. (2016), however samples made from fresh juices do not show the same tendency. Barba et al. (2015) on extraction of polyphenols using the HPP treatment similarly to total carotene and also anthocyanin content suggests, that this type of treatment compared to conventional methods can be able to enhance mass transfer processes within plant cellular tissues, as the permeability of cytoplasmatic membranes can be affected. Having said that the initial analyses of bioactive compounds could show less total phenols content, because they have not been fully extracted, compared to storing them for a week (Barba et al. 2015).

The effect of the HPP and storage on antiradical activity (DPPH)

Similarly to total phenol content DPPH appears to be stable up until the second week when its activity starts to drop. The obtained data is shown in Figure 2.

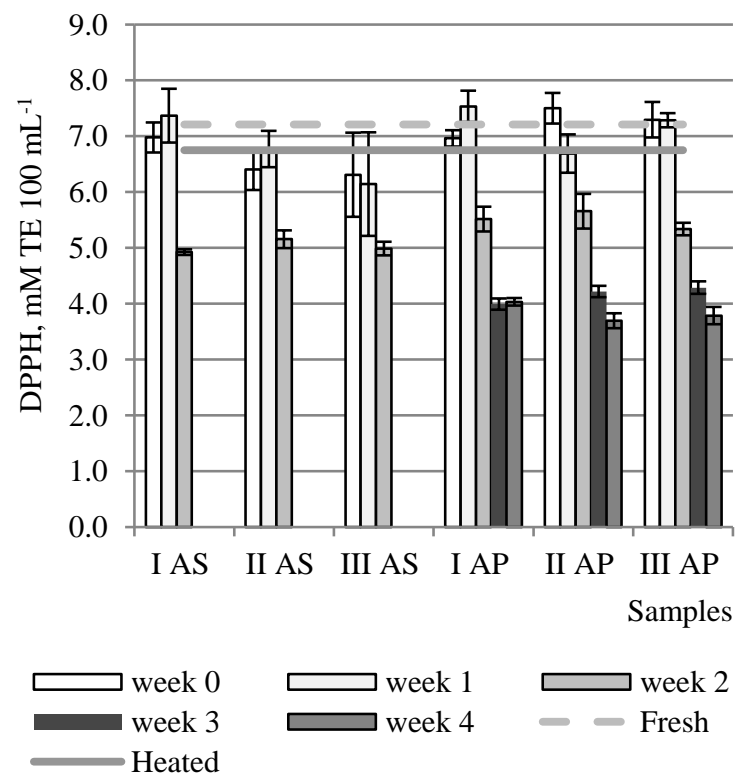

Figure 2. Antiradical activity (DPPH) of EN foods during storage, $\mathrm{mM}$ TE $100 \mathrm{~mL}^{-1}$
The antiradical activity of EN foods after the HPP isn't significantly different from samples without applied HPP and no significant difference was found between the applied pressures $(\mathrm{p}<0.05)$. Although a significant change was observed during storage where the DPPH gradually decreased which coincides with findings of Andrés et al. (2016) and Oey et al. (2008). The highest mean of DPPH was found in the semi-finished ingredient sample processed at $500 \mathrm{MPa}$ before storage II AP 7.50 $\pm 0.27 \mathrm{mM}$ TE $100 \mathrm{~mL}^{-1}$, which also had the lowest antiradical activity after storing the sample for 4 weeks $\left(3.70 \pm 0.13 \mathrm{mM}\right.$ TE $\left.100 \mathrm{~mL}^{-1}\right)$.

The data analysis of several bioactive compounds to some enteral food samples showed a higher content after storing samples for one week than it was determined before storage. These findings do not fully coincide with other author findings on bioactive compound changes during storage and does suggest the need of additional testing. The sample preparation technique of one average sample volume and division between separate packages could cause an uneven distribution of ingredients that can impact the outcome of tested compounds. In literature it has also been mentioned that HPP improves the extraction of bioactive compounds from plant cellular tissues, as the permeability of cytoplasmatic membranes are affected, as this isn't an instant occurrence it may take some time to be fully detectable (Barba et al. 2015).

\section{Conclusions}

After this preliminary research it can be concluded that additional research needs to be done, to provide more data on the HPP treatment impact on enteral foods made from different ingredients and the shelf life of these products. The obtained data showed different results for the tested bioactive compounds which not always were compatible with findings of other authors. For the further research it can be suggested to evaluate and make some additional changes in the sample preparation to ensure greater reliability on the obtained data.

Over all the research showed that samples prepared from vacuum heated (semi-finished) ingredients were more stable after high pressure processing and were microbiologically safe for 4 weeks when they were stored at room temperature in direct light. Samples made 
from fresh juices showed bigger variation in contents of bioactive compounds during storage, but similarly to semi-finished samples didn't show significant changes with the applied pressure. Also samples from fresh juices in these conditions kept their shelf life only for one week before they were deemed to be ineligible for the further research.

Vitamin $\mathrm{C}$, total carotene and total phenol content in enteral food samples made from semi-finished juices slightly decreased with the increased pressure.

Initial results also show that after using the HPP at $400 \mathrm{MPa}, 500 \mathrm{MPa}$ and $600 \mathrm{MPa}$ it is possible to obtain microbiologically safe products.

\section{References}

1. Andrés V., Villanueva M.-J., Tenorio, M.-D. (2016) The effect of high-pressure processing on colour, bioactive compounds, and antioxidant activity in smoothies during refrigerated storage. Food Chemistry, Vol. 192, p. 328-335.

2. Andrés V., Villanueva M.-J., Tenorio, M.-D. (2016b) Influence of high pressure processing on microbial shelf life, sensory profile, soluble sugars, organic acids, and mineral content of milk- and soy-smoothies. LWT - Food Science and Technology, Vol. 65, p. 98-105.

3. Barba, F.J., Terefe N.S., Buckow R., Knorr D., Orlien V. (2015) New opportunities and perspectives of high pressure treatment to improve health and safety attributes of foods. A review. Food Research International, Vol. 77, p. $725-742$.

4. Carbonell-Capella J., Barbra F., Esteve M., Frigola A. (2013) High pressure processing of fruit juice mixture sweetened with Stevia rebaudiana Bertoni: Optimal retention of physical and nutritional quality Innovative Food Science \& Emerging Technologies, Vol. 18, p. $48-56$.

5. Denoya G., Nanni N., Apóstolo N.M., Vaudagna S.R., Polenta G.A. (2016) Biochemical and microstructural assessment of minimally processed peaches subjected to high-pressure processing: Implications on the freshness condition. Innovative Food Science \& Emerging Technologies, Vol. 36, p. 212-220.

6. Jones L., Watling R.M., Wilkins S., Pizer B.(2011) Cochrane Review: Nutritional support in children and young people with cancer undergoing chemotherapy. Evidence-Based Child Health: A Cochrane Review Journal, Vol. 6(4), p. 1236-1311.

7. Kampuse S., Ozola L., Straumite E., Galoburda R. (2015)
Quality parameters of wheat bread enriched with pumpkin (Cucurbita Moschata) by-products Acta Universitatis Cibiniensis Series E: Food Technology, Vol.19 (2), p. 3-14.

8. Kerch G., Sabovics M., Kruma Z., Kampuse S., Straumite E. (2011) Effect of chitosan and chitooligosaccharide on vitamin $\mathrm{C}$ and polyphenols contents in cherries and strawberries during refrigerated storage. European Food Research and Technology, Vol. 233(2), p. 351-358.

9. Kirse A., Karklina D., Muizniece-Brasava S., Galoburda R. (2015) High pressure processing for pea spread shelf life extension: a preliminary study. In: The 4th Biannual CER Comparative European Research Conference; International Scientific Conference for Ph.D students of EU countries, London, p. 149-15.

10. Landl A., Abadias M., Sarraga C., Vinas I., Picouel P.A. (2010) Effect of high pressure processing on the quality of acidified Granny Smith apple purée product. Innovative Food Science and Emerging Technologies, Vol. 11, p. 557-564.

11. Moor U., Karp., Poldma P., Pae A. (2005) Cultural systems affect content of anthocyanins and vitamin $\mathrm{C}$ in strawberry fruits European Journal of Horticultural Science, Vol. 70 (4), p. 195-201.

12. Oey I., Van der Plancken I., Van Loey A. (2008) Does high pressure processing influence nutritional aspects of plant based food systems? Trends in Food Science \& Technology, Vol. 19(6), p. 300-308.

13. Priecina L., Kārklina D. (2014) Natural Antioxidant Changes in Fresh and Dried Spiecies and Vegetables International Journal of Biological, Biomolecular, Agricultural, Food and Bioechnical Engineering, Vol. 8 (5), p. 492-496.

14. Rozenbergs V. (2011) Uzturamācība [Nutrition] in Latvian) [accessed on 14.02.2017]. Available: http://www.academia.edu/22728396/Uztura mācība Nut rition_in_Latvian

15. Weimann A., Braga M., Harsanyi L., Laviano A., Ljungqvist O., Soeters P., Jauch K.W., Kemen M., Hiesmayr J.M., Horbach T., Kuse E.R., Vestweber K.H. (2006) ESPEN Guidelines on Enteral Nutrition: Surgery including Organ Transplantation. Clinical Nutrition, Vol.25, p. 224-244.

16. Yu L., Haley S., Perret J., Harris M., Wilson J., Haley S. (2003) Antioxidant properties of bran extracts from Akron wheat grown at different locations. Journal of Agriculture and Food Chemistry, Vol. 51(6), p. 1566-1570. 